\title{
Ultrasound Assisted Pretreatments Applied to Cupuaçu Husk (Theobroma grandiflorum) from Brazilian Legal Amazon for Biorefinery Concept
}

\author{
Nicole Marasca, ${ }^{a}$ Isabella A. Cardoso, ${ }^{b}$ Magale K. D. Rambo, ${ }^{\oplus a}$ Daniel A. Bertuol, ${ }^{\circ}$ \\ Michele C. D. Rambo, ${ }^{\circledR}$ Emerson A. Guarda ${ }^{e}$ and Elisandra Scapin ${ }^{\circledR} *, a, b, f$ \\ aPrograma de Pós-Graduação em Ciências do Ambiente (Ciamb), \\ Universidade Federal do Tocantins (UFT), 77001-090 Palmas-TO, Brazil \\ ${ }^{b}$ Laboratório de Química, Engenharia Ambiental, Universidade Federal do Tocantins (UFT), \\ 77001-090 Palmas-TO, Brazil \\ 'Laboratório de Processos Ambientais (LAPAM), Universidade Federal de Santa Maria (UFSM), \\ 97105-900 Santa Maria-RS, Brazil \\ 'Instituto Federal de Educação, Ciência e Tecnologia do Tocantins (IFTO), \\ 77020-450 Palmas-TO, Brazil \\ eLaboratório de Pesquisa em Química Ambiental e de Biocombustíveis (LAPEQ), \\ Universidade Federal do Tocantins (UFT), 77001-090 Palmas-TO, Brazil

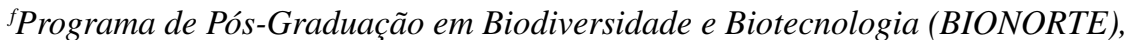 \\ Universidade Federal do Tocantins (UFT), 77001-090 Palmas-TO, Brazil
}

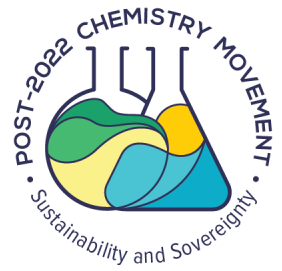

Cupuaçu husk $(\mathrm{CH})$ is the waste of a common fruit from a native species of the Brazilian Legal Amazon. The current study investigated the influence of ultrasound (US) combined with aqueous, acid, alkaline, and ionic liquid (IL) pretreatments on the chemical and physical aspects of $\mathrm{CH}$ and the yield of chemical platforms production, 5-hydroxymethylfurfural (HMF) and furfural (FF), using IL. Scanning electron microscopy, X-ray diffraction (XRD) and Fourier transform infrared spectroscopy were used to feature the raw and pretreated biomass. The highest levels of glucose $\left(9.90 \mathrm{~g} \mathrm{~L}^{-1}\right)$ were observed in the liquid fraction resulting from the acid + US pretreatment followed by acid hydrolysis. The IL + US pretreatment recorded the best performance in removing lignin. Based on XRD analyses, ultrasound increased crystallinity of all pretreated samples as a result of the removal of cellulose's amorphous fraction. However, it promoted accessibility to adopted reagents by increasing biomass exposure due to cavitation. The best yields of HMF and FF were recorded from hydrolysis of the solid fraction resulting from the acid + US (12.94\%) and alkaline + US (48.84\%) pretreatment, respectively. These results indicate satisfactory performance of ultrasound assisted pretreatments to the simplified and economic conversion of biomass into value-added products.

Keywords: pretreatment, ultrasound, cupuaçu husk, biorefineries, furanic compounds

\section{Introduction}

Cupuaçu (Theobroma grandiflorum) is a fruit native to the Brazilian Amazon, predominant produced in Brazilian Legal Amazon. ${ }^{1,2}$ Its commercialization increases every year in the national and international markets through the sale of its pulp. ${ }^{3}$ Approximately $43 \%$ of the fruit is

*e-mail: scapin@mail.uft.edu.br

Editor handled this article: Teodoro S. Kaufman composed of husk, with around 172,000 ton of this residue being generated per year. ${ }^{4,5}$

The use of this large available amount of cupuaçu husk as a source of lignocellulosic biomass could contribute to Amazon biome preservation. Once it would encourage the maintenance of native Amazon species, which have been suffering from a wide process of deforestation and insertion of agricultural monocultures, causing serious environmental damages. ${ }^{6}$

However, one of the main obstacles for utilization the lignocellulosic materials in a competitive manner lies on 
development of low-cost processing technologies that can be used on an industrial scale. ${ }^{7}$ Pretreatment is the process lignocellulosic materials are subjected to in order to remove lignin, broaden surface area, decrystallize cellulose and depolymerize the holocellulosic fraction to make biomass more accessible for the obtainment of carbohydrates necessary to bioconversion. ${ }^{8}$

Several pretreatment technologies are described in literature. Alkaline and dilute acid pretreatments stood out among the most common ones given their good efficiency in increasing cellulose accessibility, hemicellulose solubilization, and lignin removal at lower costs and less formation of inhibitors. ${ }^{9,10}$ Although it is a more recent technique, the pretreatment with ionic liquids has been widely assessed. Its high performance in cellulose and lignin solubilization at moderate temperature and pressure conditions, as well as the possibility of reuse, are some major features. ${ }^{11,12}$ Water based pretreatments, like liquid hot water (LHW) and steam explosion, have been extensively explored. However, few studies have investigated the efficiency of water as solvent under mild and less aggressive conditions for the environment. ${ }^{13,14}$

Ultrasound energy intensifies mass and heat transfer through acoustic cavitation, in which small microcavities collapse promoting mechanical effects on lignocellulosic materials, such as cell wall rupture and particle size reduction, contributing to solvent permeation and consequent increase in its effects during pretreatment. ${ }^{15}$ Several studies have assessed ultrasound in combination with other techniques aiming at the facilitated conversion of raw biomass into value-added chemicals. ${ }^{16}$ Bizzi et al. ${ }^{17}$ investigated the use of ultrasound assisting acid hydrolysis applied to different feedstock wastes in furfural synthesis. The results showed that ultrasound allowed to get higher yields than using the conventional mechanism (mechanical stirring). Ultrasound has been demonstrated an useful technology for optimizing biomass waste valorization, with fewer processes, shorter reaction times and lower temperatures. ${ }^{18}$

Regarding the multiple applications for pretreated lignocelulosic biomass, one of the most promising is to produce high value added chemicals such as 5-hydroxymethylfurfural (HMF) and furfural (FF). These compounds are remarkable for their applicability in the synthesis of other chemical products and fuels. ${ }^{19}$ The utilization of ionic liquids also as catalysts in the monomeric sugars dehydration reaction for furanics production have been noticed for the good performance and eco-friendly nature of these salts. ${ }^{20}$

In view of the research importance related to the effects and applicability of new pretreatment technologies for fruit waste materials in biorefineries and in high value added chemicals production, the present study aims to investigate the process of cupuaçu husk pretreatment by using ultrasound with different solvents followed by dilute acid hydrolysis. Changes in physical and chemical properties of assessed samples were observed via scanning electron microscopy (SEM), X-ray diffraction (XRD), and Fourier-transform infrared (FTIR) analysis. The glucose content in pretreated samples, as well as HMF and FF yields were determined through high-performance liquid chromatography (HPLC).

\section{Experimental}

\section{Sample preparation}

The cupuaçu husk $(\mathrm{CH})$ was supplied by Santa Luzia's farm, in Miranorte City, Tocantins State, Brazil. Afterwards the samples were broken into pieces of approximately $2 \mathrm{~cm}$, and dried in oven at $60^{\circ} \mathrm{C}$ (SolidSteel SSD 110L, Piracicaba, Brazil) for $24 \mathrm{~h}$. After this, $\mathrm{CH}$ were ground in Wiley mill (Start FT 50-Fortinox, Piracicaba, Brazil), sieved in 22 mesh, until they reached the mean size of $515 \mu \mathrm{m}$. Samples were stored in airtight flasks for further analysis.

\section{Biomass pretreatments}

Pretreatments consisted of using $3 \mathrm{~g}$ of raw biomass with distilled $\mathrm{H}_{2} \mathrm{O}$ (aqueous), $5 \%$ (v/v) $\mathrm{HCl}$ (acid), $4 \%$ $(\mathrm{m} / \mathrm{v}) \mathrm{NaOH}$ (alkaline) and 1-butyl-3-methylimidazolium chloride [BMIM] $[\mathrm{Cl}]$ (ionic liquid) at ratio 1:10 m/v. Each pretreatment was taken to ultrasonic bath $(100 \mathrm{~W}$ and $40 \mathrm{kHz}$ ) (SolidSteel 3.8 L, Piracicaba, Brazil) for $30 \mathrm{~min}$, at mean temperature of $35^{\circ} \mathrm{C}$ (SolidSteel 3.8 L, Piracicaba, Brazil). The material was filtered, and the solid fraction of it was dried in oven (SolidSteel SSD 110 L, Piracicaba, Brazil) at $80{ }^{\circ} \mathrm{C}$ for $12 \mathrm{~h}$, and stored in airtight flasks. All pretreatments were performed in triplicate.

The recovery of solid yield was determined through the initial amount of raw biomass and the remaining mass after the pretreatments, based on equation 1 .

Solids recovery $(\%)=\frac{\text { final amount of biomass }(\mathrm{g})}{\text { initial amount of raw material }(\mathrm{g})} \times 100$

\section{Proximate analysis}

Moisture, ash, and volatile matter contents were determined for raw biomass, through procedures standardized by ASTM (American Society of Tests and Materials). ${ }^{21-23}$

Moisture was determined by drying the biomass in stove (SolidSteel SSD $110 \mathrm{~L}$, Piracicaba, Brazil) at $105 \pm 5{ }^{\circ} \mathrm{C}$ for $12 \mathrm{~h}$ until reaching constant mass. ${ }^{21}$ 
The ash content was estimated in muffle furnace at $575{ }^{\circ} \mathrm{C}$ (SolidSteel, 6.7 L, Piracicaba, Brazil) for $4 \mathrm{~h} .{ }^{22}$

The volatile matter was also obtained in muffle furnace (SolidSteel, 6.7 L, Piracicaba, Brazil) at $800^{\circ} \mathrm{C}$ for 8 min. ${ }^{23}$

The fixed carbon content was indirectly determined by the sum of moisture, ash, and volatile matter contents subtracted from 100 .

\section{Extractives}

Untreated $\mathrm{CH}$ extractives determination was performed based on an adaptation of NREL/TP-510-42619 procedure. ${ }^{24}$ Approximately $3 \mathrm{~g}$ of biomass properly wrapped in a cartridge was taken to the Soxhlet extractor, in which was added $190 \mathrm{~mL}$ of ethanol (95\%)-reaction time was optimized to $10 \mathrm{~h}$. The material was air-dried for $48 \mathrm{~h}$ after the end of reflux. The content of extractives was calculated by weighing and subtracting the final and initial samples.

\section{Cellulose and hemicellulose analysis}

Hemicellulose was determined based on the methodology developed by the Association of Official Analytical Chemists (AOAC International). ${ }^{25}$ This methodology lies on the difference between neutral detergent fiber (NDF) and acid detergent fiber (ADF) of the material obtained by using a fiber digester (NL 61- 02). Cellulose proportion was obtained by subtraction between ADF and total lignin. The holocellulose fraction was determined through the sum of cellulose and hemicellulose contents before and after pretreatments.

\section{Hydrolysis of raw biomass}

The hydrolysis of raw biomass was performed according to NREL/TP-510-42618 protocol. ${ }^{26}$ The procedure consisted of adding $3 \mathrm{~mL}$ of sulfuric acid (72\% v/v) into $300 \mathrm{mg}$ of raw and treated biomass, then the samples were subjected to thermal bath $\left(50^{\circ} \mathrm{C}\right)$ for $1 \mathrm{~h}$, and the content was stirred every $10 \mathrm{~min}$. Subsequently $84 \mathrm{~mL}$ of distilled water was added to the samples, which were autoclaved (vertical autoclave, Phoenix, Araraquara, Brazil) at $120^{\circ} \mathrm{C}$ for $1 \mathrm{~h}$.

From the liquid fraction of the hydrolysate, the content of glucose and xylose was determined, as well as the contents of glucan and xylan using the equation 2, based on that same protocol.

$$
\mathrm{C}_{\text {polymeric }}=\mathrm{C}_{\text {monomeric }} \times \text { correction factor }
$$

where, $\mathrm{C}_{\text {polymeric }}$ : concentration of glucan or xylan $\left(\mathrm{g} \mathrm{L}^{-1}\right)$; $\mathrm{C}_{\text {monomeric }}$ : concentration of glucose or xylose $\left(\mathrm{g} \mathrm{L}^{-1}\right)$; correction factor $=0.90$ for $\mathrm{C}-6$ sugars and 0.88 for $\mathrm{C}-5$ sugars.

\section{Hydrolysis of pretreated samples}

For pretreated samples, the acid hydrolysis was performed according to Guo et al. ${ }^{27}$ using $1 \mathrm{~g}$ of biomass and $20 \mathrm{~mL}$ of dilute sulfuric acid $(2 \% \mathrm{v} / \mathrm{v})$ in a $250 \mathrm{~mL}$ Erlenmeyer flask. The solutions were incubated at $121^{\circ} \mathrm{C}$ for $15 \mathrm{~min}$, and then the hydrolysates were cooled to room temperature and filtrated. The liquid fractions obtained were used to determine glucose contents.

\section{Lignin content}

Klason (KL) and acid soluble lignin (ASL) contents were obtained based on the NREL/TP-510-42618 protocol. ${ }^{26}$ After acid hydrolysis, the remaining solids were filtrated and heated until $105^{\circ} \mathrm{C}$ in stove (SolidSteel SSD 110 L, Piracicaba, Brazil) to determine the acid insoluble residue (AIR). Subsequently, they were taken to muffle furnace at $575^{\circ} \mathrm{C}$ to determine the acid insoluble ash (AIA). $\mathrm{KL}$ was quantified based on the difference between the AIR and AIA contents. ASL was determined through UV-Vis spectrophotometry (Global Analyzer, São Paulo, Brazil) applied to the liquid fraction of hydrolysates at wavelength of $294 \mathrm{~nm}$. The total lignin (TL) content was calculated by summing KL to ASL.

\section{X-ray diffraction analysis}

Raw and pretreated biomass crystallinity was measured in X-ray diffractometer (XRD) (Bruker D8 Advance, Karlsruhe, Germany). Samples were previously dried at $80{ }^{\circ} \mathrm{C}$. Scanning covered the $5^{\circ}<2 \theta<35^{\circ}$ range with $\mathrm{Cu} \mathrm{K} \alpha$ radiation source at 0.05 scanning interval and 10-second duration.

Crystallinity index was calculated through the intensity method, ${ }^{28}$ based on equation 3 .

$\mathrm{CRI}=\frac{\mathrm{Ic}-\mathrm{Ia}}{\mathrm{Ic}} \times 100$

where, CRI: crystallinity index; Ic: intensity at $22-23^{\circ}$; Ia: intensity at $18-19^{\circ}$.

Fourier transform infrared spectroscopy analysis (FTIR)

Infrared spectra (IR) of raw and pretreated $\mathrm{CH}$ were analyzed to assess the behavior of characteristic bands of carbohydrates. FTIR spectrometer (FT-IR CARY 630, 
Agilent Technologies, Santa Clara, CA, USA) was used at reading range from 650 to $4000 \mathrm{~cm}^{-1}$, with $0.4 \mathrm{~nm}$ increment and average of 32 scans.

\section{Scanning electron microscopy analysis (SEM)}

The high-resolution images taken in scanning electron microscope (Shimadzu SSX-550, Kyoto, Japan) allowed assessing $\mathrm{CH}$ morphology and aspect before and after pretreatments. Samples were dried at $60{ }^{\circ} \mathrm{C}$ and covered with $\mathrm{Au} / \mathrm{Pd}$ film. The images were amplified to magnitudes ranging from 300 to $3,000 \times$, and observed at $10 \mathrm{kV}$.

\section{Synthesis of ionic liquid}

The 1- $n$-butyl-3-methyl-imidazole bromide ([BMIM][Br]) was synthesized according to Dharaskar et al. ${ }^{29}$

\section{Synthesis of HMF and FF}

Synthesis of furanic compounds was developed according to adaptation of Yi et al.,$^{30}$ using the liquid fraction of each pretreatment followed by acid hydrolysis $(5 \mathrm{~mL})$ and $2 \mathrm{~g}$ of ionic liquid in an oil bath system. Temperature and time were optimized in $140{ }^{\circ} \mathrm{C}$ and $1 \mathrm{~h}$, respectively, according to previous studies. ${ }^{31}$

\section{High-performance liquid chromatography analysis}

The monomeric sugars of the raw and pretreated samples were determined through high-performance liquid chromatography (HPLC) (Agilent 1260 infinity II, Santa Clara, United States) by using Supelcogel C-610H chromatographic column (Sigma-Aldrich, Burlington, United States), Supelguard C-610H pre-column (SigmaAldrich, Burlington, United States), and $\mathrm{H}_{3} \mathrm{PO}_{4}(0.1 \%)$ as mobile phase, at a flow of $0.5 \mathrm{~mL} \mathrm{~min}^{-1}$, total running time of $18 \mathrm{~min}$, and oven temperature set at $40{ }^{\circ} \mathrm{C}$.

HMF and FF contents were evaluated by Shimadzu chromatograph (LC-10 Avp series) using Phenomenex Luna C18 $5 \mu$ and pre-column Phenomenex C18. The eluent flow was $1 \mathrm{~mL} \mathrm{~min}^{-1}$ at $30^{\circ} \mathrm{C}$, with a total run time of $15 \mathrm{~min}$. The isocratic elution with a solution of acetonitrile/ water (1:8 with $1 \%$ acetic acid) and the detector used was UV (SPD-10A) with wavelength at $276 \mathrm{~nm}$.

All samples were previously diluted and filtered in $0.22 \mu \mathrm{m}$ polyvinylidene difluoride (PVDF) syringe.

The yields of $\mathrm{HMF}$ and $\mathrm{FF}$ were calculated using the equations 4 and 5 based on the methodology of Cai et al..$^{32}$

$\operatorname{HMF}(\%)=\frac{\mathrm{HMF}_{\mathrm{c}} \times \text { hydrolysate liquid fractions }(5 \mathrm{~mL}) / 126}{\text { cellulose } / 162} \times 100$ where, 126 is the molecular weight of the HMF and 162 is the molecular weight of the basic cellulose unit, $\mathrm{HMF}_{\mathrm{c}}$ is the concentration of HMF $\left(\mathrm{mg} \mathrm{L}^{-1}\right)$ and cellulose $\mathrm{c}_{\mathrm{c}}$ is the concentration of cellulose in the sample (mg).

$\mathrm{FF}(\%)=\frac{\mathrm{FF}_{\mathrm{c}} \times \text { hydroliate liquid fractions }(5 \mathrm{~mL}) / 96}{\text { hemicellulose }_{\mathrm{c}} / 132} \times 100$

where, 96 is the molecular weight of FF, 162 is the molecular weight of the basic unit of hemicellulose $\mathrm{FF}_{\mathrm{c}}$ is the concentration of FF $\left(\mathrm{mg} \mathrm{L}^{-1}\right)$ and hemicellulose $\mathrm{c}_{\mathrm{c}}$ is the concentration of cellulose in the sample (mg).

\section{Results and Discussion}

Raw biomass chemical featuring

Table 1 shows the composition of untreated $\mathrm{CH}$.

Table 1. Chemical composition of raw cupuaçu husk

\begin{tabular}{lc}
\hline Component & Concentration / \% \\
\hline Moisture & $3.22 \pm 0.01$ \\
Ash & $2.36 \pm 0.37$ \\
Volatile matter & $93.35 \pm 0.60$ \\
Fixed carbon & $4.26 \pm 0.47$ \\
Extractives & $5.89 \pm 0.26$ \\
Total lignin & $11.36 \pm 0.45$ \\
Glucan & $56.49 \pm 0.33$ \\
Xylan & $15.66 \pm 0.59$ \\
\hline
\end{tabular}

Borges et al. ${ }^{33}$ analyzed the chemical composition of cupuaçu husk and found similar results regarding ash and extractive content (3.35 and 5.95\%, respectively). Moisture content is directly related to the useful life of biomass. Low moisture content $(<15 \%)$ found in $\mathrm{CH}$ inhibits the activity of microorganisms and allows safer transport and storage, even in the long term. ${ }^{34}$ The presence of large amounts of extractives can potentially interfere with the biomass characterization analysis and hydrolysis process. The low content of extractives observed in the current study $(5.89 \%)$ indicates no need of its removal since it will not affect hydrolysis efficiency due to sulfuric acid penetration inhibition. ${ }^{24}$ The high content of volatile matter in $\mathrm{CH}$ suggests potential applications for this biomass in combustion processes, since high levels of fixed carbon indicates that biomass will burn more slowly. ${ }^{35}$

Raw cupuaçu husk present a content of total lignin (11.36\%) similar to banana waste (14\%) and corncob $(15 \%){ }^{36}$ Low lignin content can be caused by mechanical stress or adverse environmental conditions..$^{37}$ The content of glucan $(56.49 \%)$ and xylan (15.66\%) in raw biomass are 
close to the 59.57 and $18.22 \%$ found by Kandu et al. ${ }^{38}$ for hard-wood after $30 \mathrm{~min}$ thermally-assisted pretreatment.

\section{Pretreatments effect on the properties of cupuaçu husk}

\section{Solids recovery}

The application of pretreatments has evidenced solids recovery higher than $80 \%$, as shown in Table 2 .

Table 2. Solids recovery after pretreatments

\begin{tabular}{lc}
\hline Pretreatment & Solids recovery / \% \\
\hline Aqueous + US & $85.48 \pm 0.81$ \\
Acid + US & $81.98 \pm 0.50$ \\
Alkaline + US & $86.64 \pm 0.65$ \\
Ionic liquid + US & $87.52 \pm 0.65$ \\
\hline
\end{tabular}

US: ultrasound.

Pretreatment yield is closely associated to global recovery of the process, in other words, the lowest mass loss leads to a lower raw material waste; consequently, it accounts for lower production costs. Idi et al.$^{39}$ found solids yield up to $69 \%$ by testing different pretreatments in cocoa husk. Rambo et al..$^{40}$ achieved up to $77 \%$ solids recovery in alkaline pretreatment applied to coconut shell.

The higher yields obtained in the current study can be associated with ultrasound applied to pretreatment processes, since severe reaction conditions, such as high temperatures and longer reaction time, are not necessary for biomass structural degradation and increased susceptibility to subsequent carbohydrate production processes. ${ }^{41}$

\section{Sugar and lignin yields}

Figure 1 express the yields of glucose, KL and ASL of pretreated biomass followed by dilute acid hydrolysis.

All the pretreatments promoted an increase in glucose content compared to raw biomass. The highest glucose content $\left(9.90 \mathrm{gL}^{-1}\right)$ was achieved in the acid + US pretreatment followed by dilute acid hydrolysis. Świątek et $a l .^{42}$ recorded similar content of glucose, about $7 \mathrm{~g} \mathrm{~L}^{-1}$, from beech wood submitted to more severe hydrolysis conditions $0.05 \mathrm{~mol} \mathrm{~L}^{-1}$ of $\mathrm{H}_{2} \mathrm{SO}_{4}$ at $200{ }^{\circ} \mathrm{C}$ for $15 \mathrm{~min}$.

Cavitation caused by ultrasound in acid + US pretreatment increases the surface area and makes it more accessible to the effects of acid solution, which in turn acts strongly on cellulosic and hemicellulosic fraction and consequent releasement of monomers and oligomers. ${ }^{43}$ Furthermore, pretreatment with diluted acid can be performed with significantly more accessible chemicals, under moderate reaction conditions and simpler operation conditions than most pretreatments. ${ }^{44}$
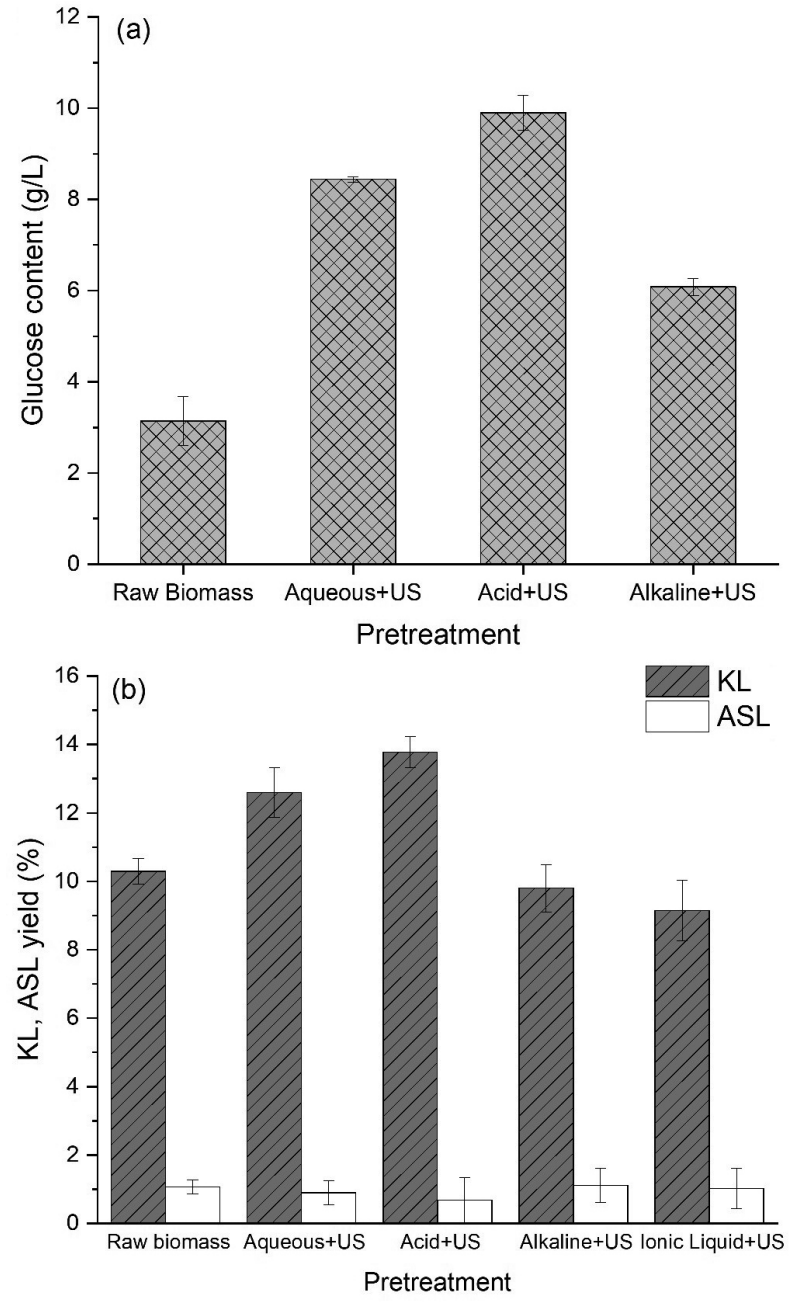

Figure 1. Glucose content (a), Klason (KL) and acid soluble lignin (ASL) (b) content in raw biomass and after different pretreatments followed by acid hydrolysis.

The combined treatment aqueous + US followed by acid hydrolysis also increased glucose content $\left(8.44 \mathrm{~g} \mathrm{~L}^{-1}\right)$ compared to raw biomass. Determination of glucose content in the hydrolysate from $\mathrm{CH}$ treated with [BMIM] [Cl] was not possible since there was no adequate column for its detection through HPLC analysis.

The hydrolysate obtained from alkaline + US pretreatment was the less effective to increase glucose content $\left(6.08 \mathrm{~g} \mathrm{~L}^{-1}\right)$ compared to $3.14 \mathrm{~g} \mathrm{~L}^{-1}$ found in raw $\mathrm{CH}$. Moreover, it showed KL and ASL rates similar to those of raw biomass. In other words, it did not evidence changes in basically any parameter, despite its usage due to recognized lignin-removal potential. ${ }^{45}$

The hydrolisate from $\mathrm{CH}$ pretreatment using $[\mathrm{BMIM}][\mathrm{Cl}]$ and ultrasound demonstrated good efficiency for lignin removal (both KL and ASL) as also observed in several studies about ionic liquid pretreatment. ${ }^{46}$ Li et al ${ }^{47}$ comparatively assessed the effects of switchgrass pretreatments based on ionic liquid and dilute acid 
utilization. The recorded results highlighted a higher efficiency of ionic liquid pretreatment in removing TL, as well as emphasized the point that acid pretreatment accomplished higher monosaccharides yield.

Similarly, Mohan et al..$^{48}$ obtained a removal of lignin (26.55 to $13.16 \%$ ) in the pretreatment of bamboo biomass with 1-ethyl-3-methylimidazolium acetate ([Emim][OAc]). Delignification of lignocellulosic biomass is an important and desired step in pretreatment processes, since it is noted that removal of lignin content makes the holocellulosic fraction of materials more accessible, both for enzymatic digestibility and chemical conversion. ${ }^{49}$

The hydrolysate from acid + US and aqueous + US pretreatments were not efficient in removing KL, however they removed ASL. The ASL contents observed in samples were slightly lower than those recorded in some literature studies about pretreatment tested in different biomasses. ${ }^{50,51}$

\section{Characteristics of raw and pretreated cupuaçu husk samples}

Samples were subjected to XRD analysis to investigate the crystallinity behavior before and after pretreatments (Figure 2). Cellulose is formed by regions of low (amorphous) and high (high crystallinity) molecular order-the amorphous region is much more sensitive to hydrolysis than the crystalline one..$^{52}$ Oftentimes, crystallinity reduction in cellulose is associated with better lignocellulosic conversion into products of interest, but it is not taken as the only factor influencing biomass digestibility or degradation. ${ }^{53}$

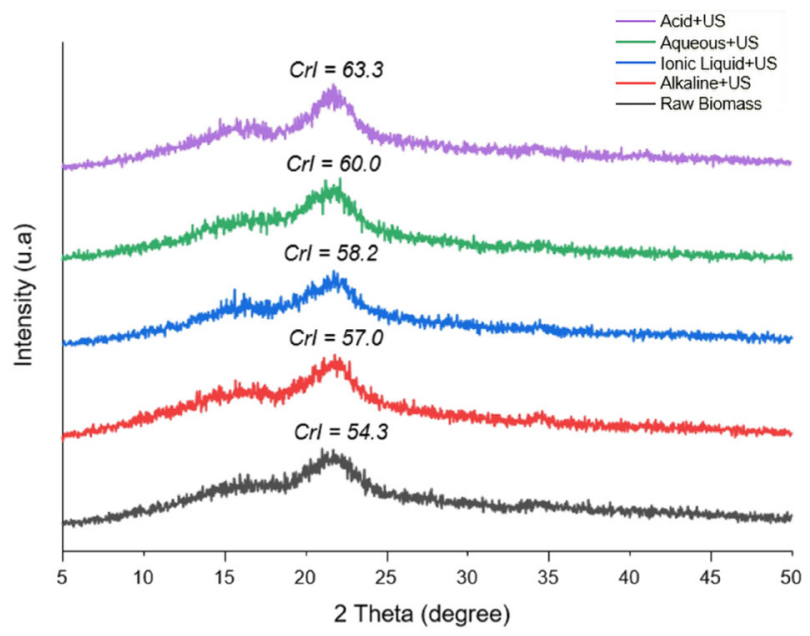

Figure 2. X-ray diffractograms of untreated and treated cupuaçu husk.

The XRD graph shows the most intense diffraction peaks at $2 \theta=22 / 23^{\circ}$. The lowest crystallinity value corresponded to raw biomass (54.3\%), which indicated that all pretreatments increased crystallinity, at the following order: alkaline + US (57\%), ionic liquid + US (58.2\%), aqueous + US (60\%) and acid + US (63.3\%). He et al..$^{54}$ found a similar behavior in their study of ultrasound pretreatment in multiple solutions, obtaining an increase in crystallinity index of eucalyptus solid waste from 31.8 to $35.5 \%$ (maximum value found) using acid pretreatment.

The association among crystallinity index, cellulose and hemicellulose content in raw biomass and pretreated samples is shown in Figure 3.

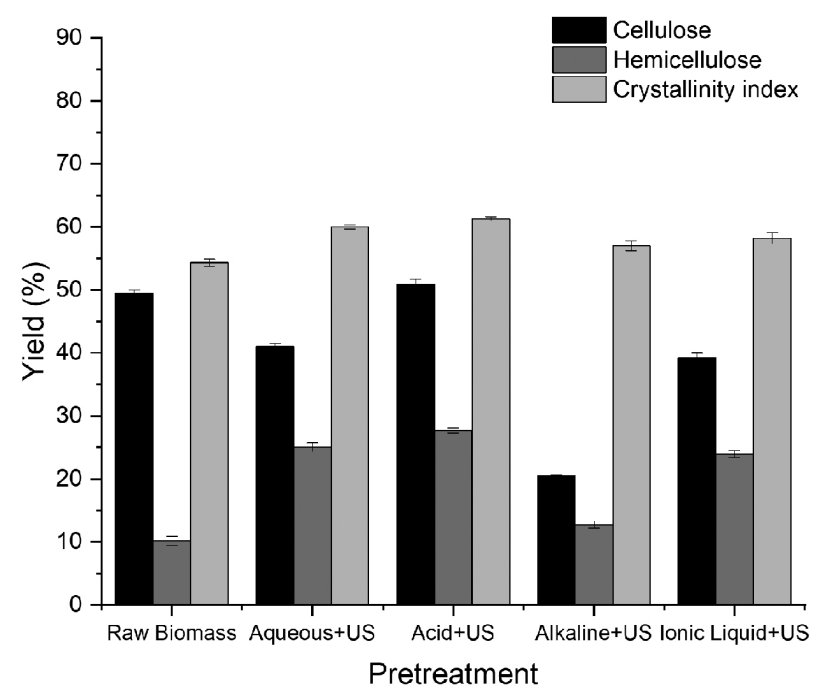

Figure 3. Crystallinity index, cellulose and hemicellulose contents from raw material and pretreated samples.

The holocellulosic fraction present in the composition of untreated $\mathrm{CH}(59.6 \%)$ is significantly higher than $25 \%$, considering the minimum value of constituent carbohydrates necessary to be used as raw material in biorefineries. ${ }^{55}$

The highest cellulose $(50.87 \%)$ and hemicellulose $(27.68 \%)$ levels were recorded for the acid + US pretreatment. This result is an indicative of increase in holocellulosic matrix, which in turn is proportional to the high content of glucose obtained in hydrolysate from this combined pretreatment (Figure 1a). This monomer is starting points for biofuel production and chemical platforms. ${ }^{56}$

Aqueous + US, ionic liquid + US and alkaline + US pretratments presented cellulose contents $(41,39.1$ and $20.5 \%$, respectively) lower than raw biomass (49.4\%) and higher crystallinity values. This finding suggests that such pretreatments may have led to degradation of cellulose amorphous fraction. ${ }^{57}$

The FTIR analysis was applied to investigate the effect of pretreatments on cupuaçu husk functional groups (Figure 4).

The intensification of peaks in region 3200 to $3400 \mathrm{~cm}^{-1}$ corresponding to the $-\mathrm{OH}$ bond indicates cellulose increase, ${ }^{58}$ on the following order: alkaline + US > 


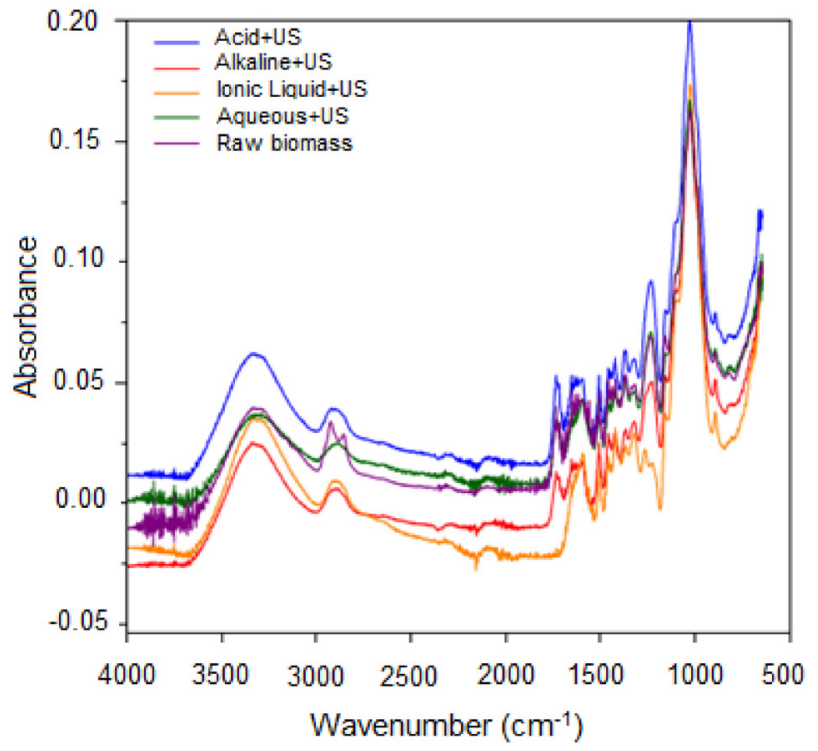

Figure 4. Infrared spectra of hydrolysate from untreated and treated samples.

ionic liquid + US $>$ aqueous + US $>$ raw biomass $>$ acid + US. This finding is in accordance with the cellulose content in these samples (Figure 3).

The spectral behavior observed between 1200 and $1300 \mathrm{~cm}^{-1}$, associated with phenolics formation, suggests that lignin content increases due to higher peaks observed in hydrolysate from acid + US and aqueous + US pretreatments when compared to raw biomass. ${ }^{59}$ This outcome is related to KL increase after these pretreatments (Figure 1b).

Details of structural changes in biomass samples before and after ultrasound pretreatments were revealed by SEM analyses (Figure 5).

A well-ordered and plane structure, with few damages in cell wall, was observed for the untreated $\mathrm{CH}$ (Figure 5a). The physical structure was gradually exposed through mild morphological damage in the sample treated in distilled water and ultrasound (Figure 5b). Sample pretreated in $\mathrm{NaOH}$ solution and ultrasound had a considerable structural disorder in its fiber (Figure 5c).

$\mathrm{CH}$ surface morphology presented significant changes due to greater acid pretreatment severity (Figure $5 \mathrm{~d}$ ) ${ }^{60}$ based on a small delignification, as shown in Figure 1c (ASL), which led to increased material porosity and exposure. Similarly, the sample pretreated with [BMIM][Cl] (Figure 5e) presented intense damages and ruptures in cell wall; this outcome may be related to the highly acidic nature of ionic liquid, which breaks hydrogen bonds in biomass and creates roughness, reduces particle size and broadens biomass surface. ${ }^{61}$

Morphological changes, observed at lower (Figures $5 \mathrm{~b}$ and $5 \mathrm{c}$ ) and higher degrees (Figures $5 \mathrm{~d}$ and 5e), resulting from pretreatments are closely associated with the ability of ultrasound to cause violent collapses of bubbles in liquids.
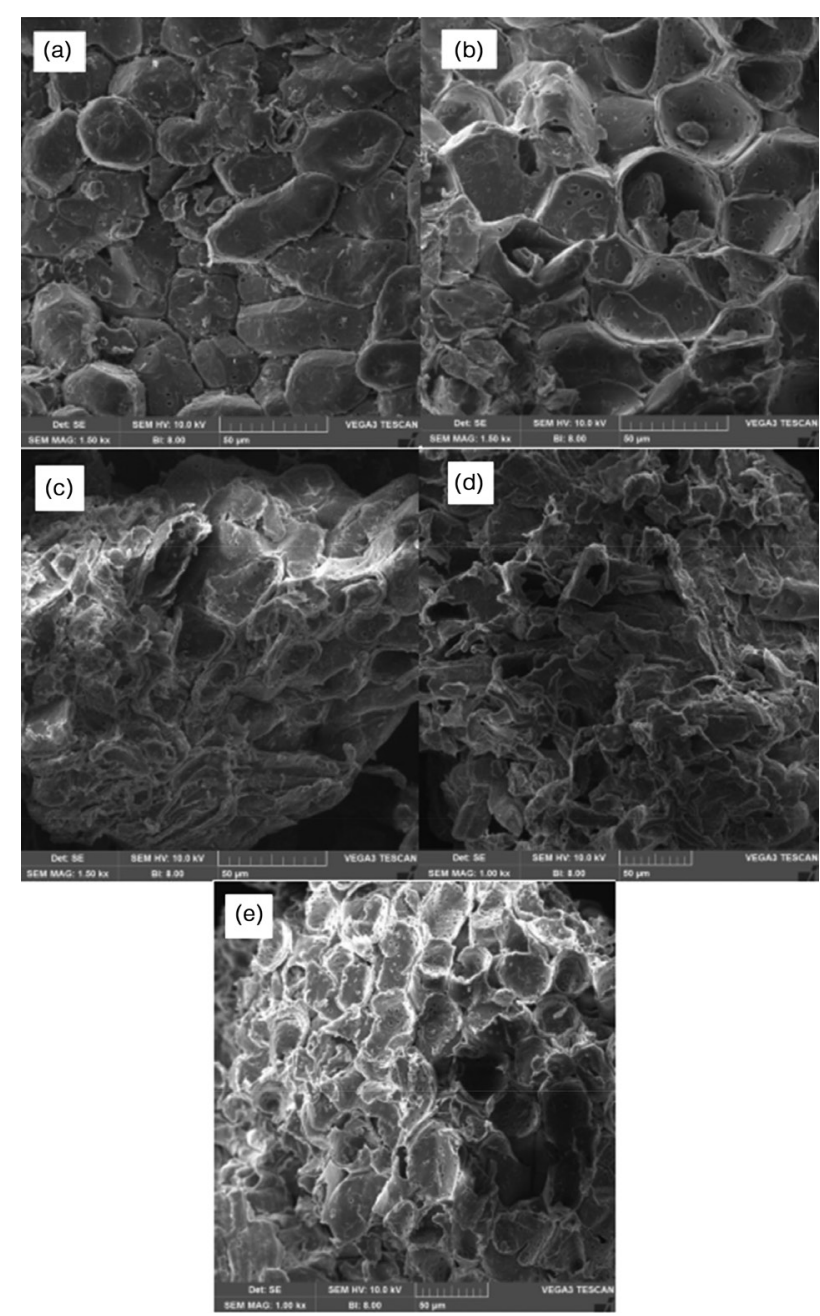

Figure 5. SEM images of untreated cupuaçu husk samples (a), after the ultrasound and aqueous (b), alkaline (c), acid (d) and ionic liquid (e) pretreatment.

This process produces physical effects on material surface with an uniform modification that promote a better action of solvents compared to the ultrasound absence. ${ }^{62}$

Furanics production using pretreated biomass hydrolysate

Figure 6 shows the yields of furanic compounds, HMF and $\mathrm{FF}$, produced using the hydrolysate liquid fraction of pretreatments whit ionic liquid [BMIM][Br] acting as solvent/catalytic.

The highest HMF yield (12.94\%) was obtained through acid + US pretreatment hydrolysate, which is accordance to the highest level of glucose recorded in this pretreatment, since HMF is mostly produced from glucose isomerization and further dehydration. ${ }^{63}$ Intermediate content of HMF was found in alkaline + US pretreatment hydrolysate (5.37\%) whereas no significant result was found using the aqueous + US (ND) hydrolysate what could be elucidated by the rehydration of HMF causing levulinic acid and/or 


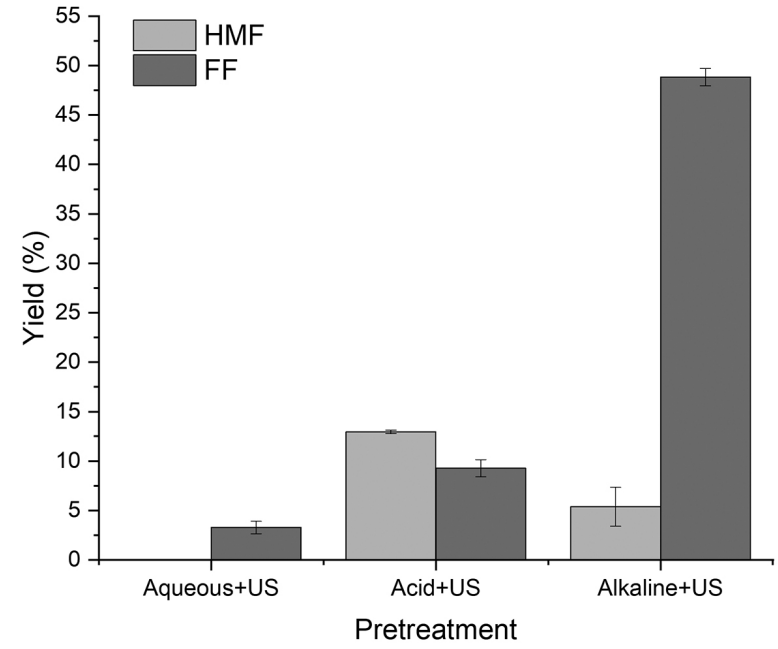

Figure 6. Yields of furanics obtained from hydrolysate of pretreated biomass.

humins formation during the synthesis reaction promoted by the aqueous character of medium. ${ }^{64}$

Regarding FF yields, a significant content was found in the reaction of [BMIM] $[\mathrm{Br}]$ with alkaline + US pretreatment hydrolysate (48.84\%). This may be explained by the greater accessibility of the amorphous hemicellulosic fraction when compared to HMF production from cellulose, as well as the high selectivity of the ionic liquids as catalysts for the hemicellulose fraction to produce pentoses and/or furfural. ${ }^{65}$ The acid + US and aqueous + US pretreatments followed by acid hydrolysis promoted lower FF yields, 9.27 and $3.28 \%$, respectively.

HMF and FF yields using ionic liquid + US pretreatment hydrolysate cannot be evaluated because there was no adequate column for its detection through HPLC.

Li et al. ${ }^{66}$ verified that HMF yields using bagasse pretreated with ionic liquid and ultrasound $(40 \mathrm{kHz}$, $30 \mathrm{~min}$ ) are higher than using untreated biomass, obtaining a maximum HMF yield of $65.72 \%$. Lower yields of furfural $(20.16 \%)$ and HMF $(5.38 \%)$ were obtained by Zulkipli et al. ${ }^{67}$ in oil palm mesocarp fiber samples pretreated ultrasound and acid $(6 \% \mathrm{v} / \mathrm{v})$ followed by sulfuric acid $(2 \% \mathrm{v} / \mathrm{v})$ hydrolysis at $140{ }^{\circ} \mathrm{C}$ for $3 \mathrm{~h}$.

Significant yields of HMF and FF recorded in this current study are important results given the usage of solely the pretreated biomass hydrolysate, in absence of additional catalysts, following the principles related to number of processes reduction and consequent cost-effective increase in the synthesis of value added chemical products.

\section{Conclusions}

The chemical composition of untreated $\mathrm{CH}$ presented low moisture, ash, lignin and extractives content, as well as satisfactory yields of cellulose, glucan and xylan, aspects favorable to its use as a residual-origin and renewable lignocellulosic raw material for bio-product manufacturing.

The XRD analysis has shown an increased in crystallinity in all ultrasound pretreatments, possibly in consequence of amorphous cellulose remotion associated with the ultrasonic energy. The highest crystallinity value (63.3\%) observed in hydrolysate derived from acid + US sample was in compliance with its best yield of glucose. The result highlights that pretreatment combining acid and ultrasound followed by dilute acid hydrolysis was the most promising method to treat cupuaçu husk in this current study.

It was observed that the hidrolysate from $\mathrm{CH}$ pretreated with [BMIM][Cl] presented the best performance related to KL and ASL removal, a fact that contributed to improve the general action of this pretreatment in delignifying raw biomass.

The highest yields of HMF (12.94\%) and FF (48.84\%) were recorded in acid + US and alkaline + US pretreatment hydrolysates, respectively, using [BMIM] $[\mathrm{Br}]$ during $1 \mathrm{~h}$ at $140{ }^{\circ} \mathrm{C}$. These satisfactory results indicated good performance of assisted ultrasound pretreatment once no additional catalysts/solvent were used during the synthesis.

\section{Acknowledgments}

The authors are grateful to Universidade Federal do Tocantins (UFT) for the support provided during the conduction of experiments and the support through the Edital Propesq No. 39/2020 (Edital Universal de Pesquisa), to CAPES (Coordenação de Aperfeiçoamento de Pessoal de Nível Superior, finance code 001) and PPGCiamb (Graduate Program in Environmental Sciences) for contributing to the manuscript translation and publication (edital No. 17/2021 and edital No. 33/2020), and finally Instituto Federal de Educação, Ciência e Tecnologia do Tocantins (IFTO) for subsides conceded by PAP/inova project No. 47/2020.

\section{Author Contributions}

Nicole Marasca was responsible for conceptualization, data curation, writing original draft, writing-review and editing; Isabella A. Cardoso for the data curation and validation; Magale K. D. Rambo for the conceptualization, data curation, visualization, writing original draft, writing-review and editing; Daniel A. Bertuol for the data curation and software; Michele C. D. Rambo for the data curation, formal analysis and funding acquisition; Emerson A. Guarda for the data curation and software; Elisandra Scapin for the conceptualization, data curation, formal analysis, funding acquisition, validation, visualization, writing original draft, writing-review and editing. 


\section{References}

1. Socha, L. B.; Pinheiro, R. B. M.; Rev. GeAS 2015, 4, 554.

2. Instituto Brasileiro de Geografia e Estatística (IBGE); Amazônia Legal 2019; https://geoftp.ibge.gov.br/organizacao_ do_territorio/estrutura_territorial/amazonia_legal/2019/ Amazonia_Legal_2019.pdf, accessed in December 2021.

3. Cohen, K. O.; Jackix, M. N. H.; Cienc. Tecnol. Aliment. 2005, $25,182$.

4. Gondim, T. M. S.; Thomazini, M. J.; Cavalcante, M. J. B.; de Souza, J. M. L.; Aspectos da Produção de Cupuaçu; EMBRAPA: Rio Branco, 2001, available at http://www. infoteca.cnptia.embrapa.br/infoteca/handle/doc/498481, accessed in December 2021.

5. Ministério da Educação (MEC); Сириаçu; 2007, available at http://portal.mec.gov.br/setec/arquivos/pdf3/publica_setec_ cupuacu.pdf, accessed in December 2021.

6. Silva Jr., C. H. L.; Pessôa, A. C. M.; Carvalho, N. S.; Reis, J. B. C.; Anderson, L. O.; Aragão, L. E. O. C.; Nat. Ecol. Evol. 2021, 5, 144.

7. Brandt, A.; Gräsvik, J.; Hallett, J. P.; Welton, T.; Green Chem. 2013, 15,550

8. Hasanov, I.; Raud, M.; Kikas, T.; Energies 2020, 13, 4864.

9. Agbor, V. B.; Cicek, N.; Sparling, R.; Berlin, A.; Levin, D. B.; Biotechnol. Adv. 2011, 29, 675.

10. Badiei, M.; Asim, N.; Jahim, J. M.; Sopian, K.; APCBEE Proc. 2014, $9,170$.

11. Dibble, D. C.; Li, C.; Sun, L.; George, A.; Cheng, A.; Çetinkol, O. P.; Benke, P.; Holmes, B. M.; Singh, S.; Simmons, B. A.; Green Chem. 2011, 13, 3255.

12. Baruah, J.; Nath, B. K.; Sharma, R.; Kumar, S.; Deka, C.; Baruah, D. C.; Kalita, E.; Front. Energy Res. 2018, 6, 141.

13. Steinbach, D.; Kruse, A.; Sauer, J.; Biomass Convers. Biorefin. 2017, 7, 247.

14. Zhuang, X.; Wang, W.; Yu, Q.; Wang, Q.; Tan, X.; Zhou, G.; Yuan, Z.; Bioresour. Technol. 2016, 199, 68.

15. Chemat, F.; Vian, M. A.; Fabiano-Tixier, A. S.; Nutrizio, M.; Jambrak, A. R.; Munekata, P. E. S.; Lorenzo, J. M.; Barba, F. J.; Binello, A.; Cravotto, G.; Green Chem. 2020, 22, 2325.

16. Subhedar, P. B.; Gogate, P. R. In Biomass Fractionation Technologies for a Lignocellulosic Feedstock Based Biorefinery; Mussatto, S. I., ed.; Elsevier: Amsterdam, 2016, p. 127.

17. Bizzi, C. A.; Santos, D.; Sieben, T. C.; Motta, G. V.; Mello, P. A.; Flores, E. M. M.; Ultrason. Sonochem. 2019, 51, 332.

18. Flores, E. M. M.; Cravotto, G.; Bizzi, C. A.; Santos, D.; Iop, G. D.; Ultrason. Sonochem. 2021, 72, 105455.

19. Eerhart, A. J. J. E.; Huijgen, W. J. J.; Grisel, R. J. H.; van der Waal, J. C.; de Jong, E.; Dias, A. S.; Faaij, A. P. C.; Patel, M. $\mathrm{K} . ; \operatorname{RSC} A d v . \mathbf{2 0 1 4}, 4,3536$.

20. Li, X.; Xu, R.; Yang, J.; Nie, S.; Liu, D.; Liu, Y.; Chuanling, S.; Ind. Crops Prod. 2019, 130, 184.
21. ASTM D3173/D3173M-17a: Standard Test Method for Moisture in the Analysis Sample of Coal and Coke, Philadelphia, 2017.

22. ASTM D3174-12(2018)e1: Standard Test Method for Ash in the Analysis Sample of Coal and Coke from Coal, Philadelphia, 2018.

23. ASTM D3175-20: Standard Test Method for Volatile Matter in the Analysis Sample of Coal and Coke, Philadelphia, 2020.

24. NREL/TP-510-42619: Determination of Extractives in Biomass; National Renewable Energy Laboratory: Golden, 2008, available https://www.nrel.gov/docs/gen/fy08/42619. pdf, accessed December 2021

25. Latimer Jr., G. W.; Official Methods of Analysis of the AOAC International, $19^{\text {th }}$ ed.; CAB Publisher: Gaithersburg, 2012.

26. NREL/TP-510-42618: Determination of Structural Carbohydrates and Lignin in Biomass; National Renewable Energy Laboratory: Golden, 2012, available at https://www. nrel.gov/docs/gen/fy13/42618.pdf, accessed in December 2021.

27. Guo, X.; Zhang, T.; Shu, S.; Zheng, W.; Gao, M.; ACS Sustainable Chem. Eng. 2016, 5, 420.

28. Sasmal, S.; Goud, V. V.; Mohanty, K.; Biomass Bioenergy 2012, $45,212$.

29. Dharaskar, S. A.; Wasewar, K. L.; Varma, M. N.; Shende, D. Z.; Yoo, C.; Arabian J. Chem. 2016, 9, 578.

30. Yi, Y.; Ha, M.; Lee, J.; Chung, C.; Chem. Eng. J. 2012, 180, 370.

31. Scapin, E.; Rambo, M. K. D.; Viana, G. C. C.; Marasca, N.; Lacerda, G. E.; Rambo, M. C. D.; Fernandes, R. M. N.; Food Sci. Technol. 2020, 40, 83.

32. Cai, C.; Liu, Q.; Tan, J.; Wang, T.; Zhang, Q.; Ma, L.; BioResources 2017, 12, 1201.

33. Borges, M. S.; Barbosa, R. S.; Rambo, M. K. D.; Rambo, M. C. D.; Scapin, E.; Biomass Convers. Biorefin. 2020, DOI: https:// doi.org/10.1007/s13399-020-00892-x.

34. Rentizelas, A. In Biomass Supply Chains for Bioenergy and Biorefining; Holm-Nielsen, J. B.; Ehimen, E. A., eds.; Woodhead Publishing: Cambridge, 2016, p. 127.

35. do Vale, A. T.; Mendes, R. M.; Aamorim, M. R. S.; Dantas, V. F. S.; Cerne 2011, 17, 267.

36. Jahirul, M. I.; Rasul, M. G.; Chowdhury, A. A.; Ashwath, N.; Energies 2012, 5, 4952.

37. Novaes, E.; Kirst, M.; Chiang, V.; Winter-Sederoff, H.; Sederoff, R.; Plant Physiol. 2010, 154, 555.

38. Kandu, C.; Shanthi, P. S.; Mahmud, A. K.; Bhattacharya, S.; Sci. Rep. 2021, 11, 11183.

39. Idi, A.; Md. Salleh, M.; Ibrahim, Z.; Mohamad, S. E.; J. Teknol. (Sci. Eng.) 2012, 59, 49.

40. Rambo, M. K. D.; de Melo, P. M.; Ferreira, M. M. C.; Rambo, M. C. D.; Bertuol, D. A.; Mota, V. L.; J. Braz. Chem. Soc. 2020, 31,904 . 
41. Rehman, M. S. U.; Kim, I.; Chisti, Y.; Han, J. I.; Energy Educ. Sci. Technol., Part A 2013, 30, 1391.

42. Świątek, K.; Gaag, S.; Klier, A.; Kruse, A.; Sauer, J.; Steinbach, D.; Catalysts 2020, 10, 437.

43. Kusmiyati, K.; Anarki, S. T.; Nugroho, S. W.; Widiastutik, R.; Hadiyanto, H.; Bull. Chem. React. Eng. Catal. 2019, 14, 705.

44. Xu, L.; Zhang, S. J.; Zhong, C.; Li, B. Z.; Yuan, Y. J.; Ind. Eng. Chem. Res. 2020, 59, 16923.

45. Wang, F. L.; Li, S.; Sun, Y. X.; Han, H. Y.; Zhang, B. X.; Hu, B. Z.; Gao, Y. F.; Hu, X. M.; RSC Adv. 2017, 7, 47990.

46. Zhang, J.; Zhang, X.; Yang, M.; Singh, S.; Cheng, G.; Bioresour. Technol. 2021, 322, 124522.

47. Li, C.; Knierim, B.; Manisseri, C.; Arora, R.; Scheller, H. V.; Auer, M.; Vogel, K. P.; Simmons, B. A.; Singh, S.; Bioresour. Technol. 2010, 101, 4900.

48. Mohan, M.; Deshavath, N. N.; Banerjee, T.; Goud, V. V.; Dasu, V. V.; Ind. Eng. Chem. Res. 2018, 57, 10105.

49. Morais, A. R. C.; Pinto, J. V.; Nunes, D.; Roseiro, L. B.; Oliveira, M. C.; Fortunato, E.; Bogel-Lukasik, R.; ACS Sustainable Chem. Eng. 2016, 4, 1643.

50. Hou, X. D.; Smith, T. J.; Li, N.; Zong, M. H.; Biotechnol. Bioeng. 2012, 109, 2484.

51. Ko, J. K.; Kim, Y.; Ximenes, E.; Ladisch, M. R.; Biotechnol. Bioeng. 2015, 112, 252.

52. Caliari, I. P.; Barbosa, M. H. P.; Ferreira, S. O.; Teófilo, R. F.; Carbohydr. Polym. 2016, 158, 20.

53. Karimi, K.; Taherzadeh, M. J.; Bioresour. Technol. 2016, 200, 1008.

54. He, Z.; Wang, Z.; Zhao, Z.; Yi, S.; Um J.; Wang, X.; Ultrason. Sonochem. 2017, 34, 136.
55. Rambo, M. K. D.; Cardoso, A. L.; Bevilaqua, D. B.; Rizzetti, T. M.; Ramos, L. A.; Korndorfer, G. H.; Martins, A. F.; J. Agron. 2011, 10, 99 .

56. Isikgor, F. H.; Becer, C. R.; Polym. Chem. 2015, 6, 4497.

57. Flórez Pardo, L. M.; Salcedo Mendoza, J. G.; López Galán, J. E.; Braz. J. Chem. Eng. 2019, 36, 131.

58. Sindhu, R.; Binod, P.; Satyanagalakshmi, K.; Janu, K. U.; Sajna, K. V.; Kurien, N.; Sukumaran, R. K.; Pandey, A.; Appl. Biochem. Biotechnol. 2010, 162, 2313.

59. Brienzo, M.; Fikizolo, S.; Benjamin, Y.; Tyhoda, L.; Görgens, J.; Renewable Energy 2017, 104, 271.

60. Awoyale, A. A.; Lokhat, D.; Sci. Rep. 2021, 11, 557.

61. Khan, A. S.; Man, Z.; Bustam, M. A.; Nasrullah, A.; Ullah, Z.; Sarwono, A.; Shah, F. U.; Muhammad, N.; Carbohydr. Polym. 2018, 181, 208.

62. Mason, T. J.; Cobley, A. J.; Graves, J. E.; Morgan, D.; Ultrason. Sonochem. 2011, 18, 226.

63. de Melo, F. C.; de Souza, R. F.; Coutinho, P. L. A.; de Souza, M. O.; J. Braz. Chem. Soc. 2014, 25, 2378.

64. Galaverna, R.; Pastre, J. C.; Rev. Virtual Quim. 2016, 9, 248.

65. da Costa Lopes, A. M.; Morais, A. R. C.; Łukasik, R. M. In Production of Platform Chemicals from Sustainable Resources; Fang, Z.; Smith Jr., R.; Qi, X., eds.; Springer: Singapore, 2017, p. 45.

66. Li, M.; Jiang, H.; Zhang, L.; Yu, X.; Liu, H.; El Gasim, A. A.; Mo L.; Haonan, J.; Lei, Z.; Xiaojie, Y.; Hui, L.; Yagoub, A. E. A.; Zhou, C.; Ind. Crops Prod. 2020, 149, 112361.

67. Zulkipli, N. A.; Yunus, R.; Zainal, A. Z.; Lim, B. Y.; 2020 DOI: http://dx.doi.org/10.2139/ssrn.3577788

Submitted: October 14, 2021 Published online: January 7, 2022 